\title{
Embryo experiments
}

\author{
C B Goodhart
}

With the publication in November 1987 of the Department of Health's white paper on Human Fertilisation and Embryology: A Framework for Legislation, ${ }^{1}$ parliament is soon going to have to think once again about the rights and wrongs of experimenting with human embryos. Based on the 1984 report of the Warnock committee $^{2}$ the white paper proposes setting up a statutory licensing authority which would license experiments on human embryos in vitro during the first 14 days after fertilisation (excluding time when development is halted by freezing), after which any surviving embryos would have to be destroyed.

Since even those who feel that they can be trusted to behave ethically without interference from the law will scarcely want to make an issue of this, and would anyway be happy enough with the Warnock proposals, some form of restrictive legislation is now to be expected. Warnock will, however, be opposed by those who, believing for religious or other reasons in the sanctity of human life from fertilisation, would not allow any manipulation of even the earliest embryos when that is intended or expected to result in their destruction. They are, after all, already biologically distinct human organisms, differing from full term babies only in size and appearance - and what has that got to do with the right to life?

Nowadays such an extreme position is unlikely to be accepted, however, and any opposition to Warnock will probably concentrate on the line taken by $\mathrm{Mr}$ Enoch Powell's Unborn Children (Protection) Bill, which did gain a good deal of support in the 1984-5 session of parliament, even though it failed in the end for lack of time. This would have allowed the use of eggs fertilised in vitro to make a woman pregnant, where this could not be achieved by natural means, but experimenting with them simply to extend scientific knowledge would not be permitted. To quote from an article of Mr Powell's in The Times of 14 December 1987 , his bill invited the House of Commons to declare that "it was abhorrent to create or use embryos other than to procure the birth of a normal human child." He did not object to fertilising several eggs where the

Gonville \& Caius College, Cambridge CB2 1TA

C B Goodhart, PHD, fellow

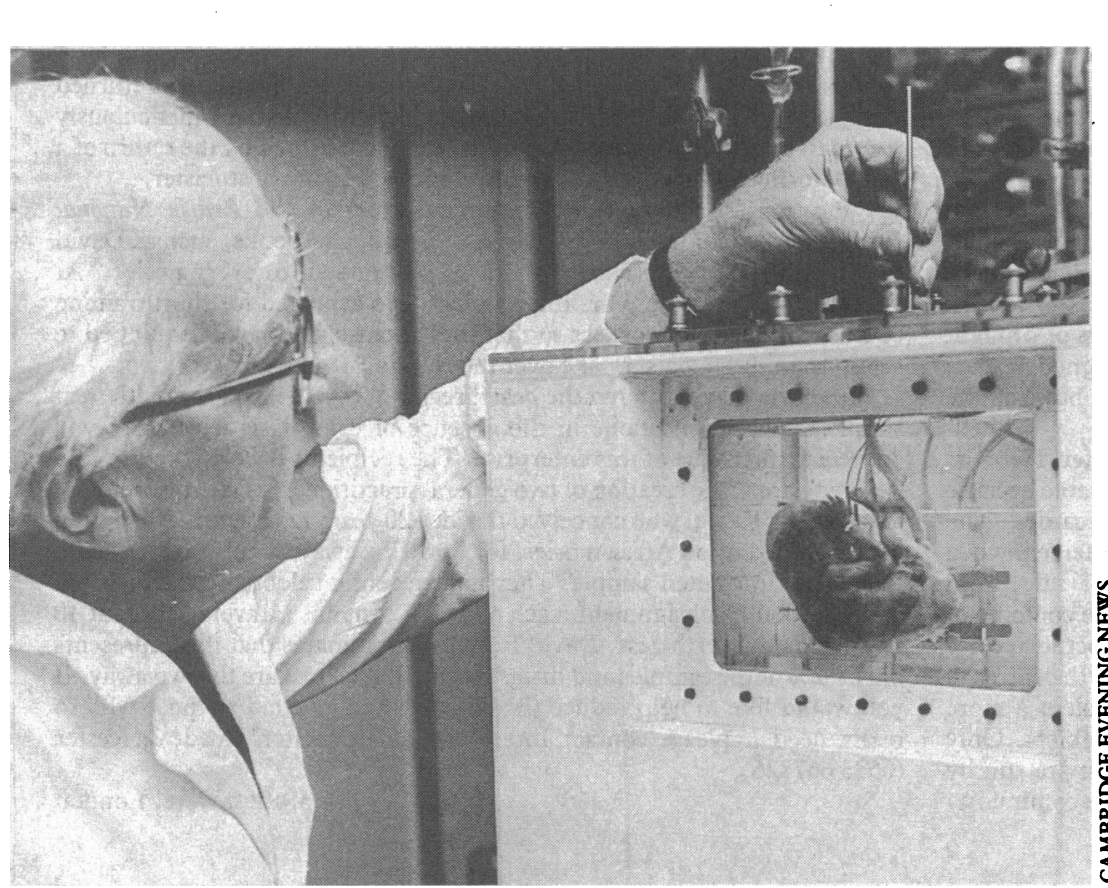

The late Dr Lawrence Lawn intention was to put the resulting embryos back into a woman to complete their normal development, and he recognised that in doing so some surplus embryos might be produced and that "there would be no reason to outlaw the creation of these extra embryos; but it would be unlawful to use them for any other purpose, such as laboratory examination involving their destruction, and they would not be preserved."

Both Mr Powell and Lady Warnock took it for granted that the embryo (or "pre-embryo" as it is sometimes called before there are any signs of embryonic differentiation-not that this affects the argument), whether or not it is a "human being," is right from the start much more than the same as any other small piece of tissue, since it is potentially capable of being born as a person with full human rights. And, leaving aside the question-begging definition of it as a human being, there can be no doubt that a newly fertilised egg in its mother's womb is capable of developing as a normal baby, or indeed two if they are twins. But there is one very important difference between an egg taken from a woman to be fertilised outside her body, and one fertilised naturally inside her. This is that the embryo conceived in vitro, although in all other respects exactly the same as one in vivo, is not capable of completing its normal development. An embryo in utero will grow into a baby unless it dies or is killed, but it will not do so in vitro unless some positive action is taken to put it into a woman's uterus.

\section{A tenable point}

At fertilisation an embryo does start on its life as a separate human organism, genetically as distinct from both its parents as it will ever be. And there are those who hold that with this it becomes endowed with an immortal soul so that to kill it, or even to refrain from doing what may be required to keep it alive, is tantamount to murder. But this does not seem to be $\mathrm{Mr}$ Powell's position, any more than Lady Warnock's, since he has no objection to killing surplus embryos, but only experimenting with them before they die. That is a tenable point of view, but so is Lady Warnock's that if an embryo is going to die anyway it might as well be used for experiments before it does so, especially if these are expected to improve the prospects for other embryos to be conceived in the future. It will be for parliament to judge between the two.

But the one thing that must be clear is that there is a real distinction between doing experiments with an embryo produced in vitro, which is incapable of leading to the birth of a normal child without some quite extraordinary intervention from outside involving finding a woman willing and able to carry it to term, and experimenting with an embryo or fetus already inside its mother, which normally can be expected to complete its development. To do that might indeed be unacceptable, even if perhaps not so very much more so than to kill the child by procuring its abortion otherwise than for serious medical reasons. For example, one can see that there might be ethical objections to experimenting with preimplantation blastocysts in utero, or even with fertilised eggs flushed out by postcoital lavage, on the grounds that these could have completed their development had they not been artificially interfered with, which would not apply to culturing an embryo in vitro beyond the proposed 14 
day limit, when the embryo is bound to die soon whatever is done to it.

Although the white paper, like the Warnock committee, was concerned principally to control work on very early human embryos, before they could implant, any legislation resulting from it is likely also to cover experimentation on later fetuses, including those separated from the mother by abortion. One of the functions of the proposed statutory licensing authority is defined by paragraph 15 of the white paper as "to license research projects involving the use of human embryos"; and under paragraph 33: "If research is permitted under licence from the SLA, the Government proposes that the Authority will not be able to give a licence for the use of embryos beyond fourteen days, or after the appearance of the primitive streak, whichever is the earlier. Use beyond this time would therefore be a criminal offence." Although this may have been intended to refer only to early embryos in vitro, as it stands it would apply also to later fetuses alive in utero, or after abortion when they may live for minutes if not hours, and are then certainly "in vitro."

A case could in fact be made for allowing experiments with a fetus in utero if it had been decided to destroy it later by legal abortion. The very idea of this may seem repugnant: but what if a mother who had sadly accepted advice that her much wanted baby was so defective that it would be better aborted were to be persuaded to allow experiments on it which might help to avoid such tragedies in the future? She might get some consolation from the thought that her baby's life would not have been wholly wasted, as it would be if it were aborted straight away, and to do this would probably not be unlawful at present, although it might be if the white paper proposals were accepted.

\section{Experiments with late aborted fetuses}

Finally there is the question of experimenting with legally aborted previable fetuses, which can live for some time after delivery but which will always die in the end. For example, in 1970 the late Dr Lawrence Lawn, of the Department of Investigative Medicine at Cambridge, conducted some well publicised experi- ments on living aborted human fetuses of 16-18 weeks' gestation, kept alive in his apparatus for up to three hours, with a view to developing an artificial placenta to be used for saving very premature babies (figure). Some of the photographs published in the popular press at the time may not have been for the squeamish, but there was never any suggestion that this work was illegal. And in 1969 Coutts and MacNaughton (now Sir Malcolm MacNaughton, past president of the Royal College of Obstetricians and Gynaecologists) reported on some experiments in which human fetuses, obtained after therapeutic termination of pregnancy at between 13 and 22 weeks' gestation, were kept alive for two hours outside the uterus to be perfused with radioactive cholesterol. ${ }^{3}$ That might well constitute a criminal offence under the legislation now being considered, but whether it should be is at least arguable, and this seems to have been a point which was not addressed by the Warnock committee.

There haven't been many recent reports of experimental work in Britain with later human embryos and fetuses, either before or after abortion, but this could be done at any time and might be expected to produce medically useful results. It is true that such work would to some extent be regulated by the 1972 Peel report guidelines, ${ }^{4}$ which are about to be reviewed by a new government committee, but it would be a good thing if they could now be given the force of law. Although the present white paper is concerned almost entirely with very early pre-embryos conceived in vitro, experiments with much older fetuses destined for abortion also raise important ethical and legal questions which ought not be to overlooked in any proposed new legislation. 1 Department of Health and Social Security. Human fertilisation and embryology: a
framework for legislation. London: HMSO, 1987. (Cmnd 259.)

2 Committee of Inquiry into Human Fertilisation and Embryology. Report. London: HMSO, 1984. (Warnock report.)

3 Coutts JRT, MacNaughton MC. The metabolism of $\left(4-{ }^{14} \mathrm{C}\right)$ cholesterol in the pre-viable human fetus. $\mathcal{F}$ Endocrinol $1969 ; 44: 481-8$

4 Department of Health and Social Security, Scottish Home and Health Department, and Welsh Office. The use of fetuses and fetal material for research. London: HMSO, 1972. (Peel report.)

(Accepted 4 August 1988)
Are worn utensils coated with polytetrafluorethylene carcinogenic and should they be discarded?

This question is more complex than it seems. Polytetrafluorethylene (commonly known as Teflon, a Dupont registered trademark) and related fluorocarbon resins are per se chemically inert materials which come under no suspicion in respect of chronic toxicity or carcinogenicity. In keeping with this no evidence of toxicity was seen in rats fed on a diet containing $25 \%$ polytetrafluorethylene for 90 days. So should flakes of polytetrafluorethylene find their way from worn kitchen utensils into food there would be no grounds for concern.

A more important question relates not to the flaking of the polytetrafluorethylene surface but to its decomposition under conditions of accidental overheating. Almost any organic material when overheated gives rise to an array of pyrolysis products, which include several toxic or carcinogenic substances, or both, of various chemical types-including polycyclic aromatic hydrocarbons. Foodstuffs are not exceptional. Thus, overheated and burnt foodstuffs contain traces of known carcinogens. It is in this context that the consequences of overheating polytetrafluorethylene need to be viewed. What happens if polytetrafluorethylene is overheated? Are carcinogens or other toxins produced and, if so, is exposure to them more dangerous than exposure to overheated foodstuffs?

Toxins may be produced by heating polytetrafluorethylene to high temperatures. ' Decomposition products of polytetrafluorethylene heated to between $350^{\circ} \mathrm{C}$ and $450^{\circ} \mathrm{C}$ form a finely divided white "sublimate" of its telomers. The inhalation of this sublimate of these telomers may cause what has been called polymer fume fever. This takes the form of an influenza-like episode starting two to three hours after exposure and clearing up spontaneously within 36 to 48 hours.

Signs suggestive of polymer fume fever have never been observed in tests on animals. On the other hand, decomposition products obtained at higher temperatures (starting around $400^{\circ} \mathrm{C}$ ) contain toxins including carbonyl fluoride, octafluoroisobutylene, and hydrogen fluoride (hydrofluoric acid). These have been shown to be toxic in animal tests, but only at dose levels which could never be reached in the ordinary kitchen.

In the polytetrafluorethylene processing industry cases of polymer fume fever have occurred where ventilation was inadequate or where tobacco products became contaminated with polytetrafluorethylene. People have developed polymer fume fever in the home after unattended utensils have heated to more than $340^{\circ} \mathrm{C}$. There is, however, no known association between polymer fume fever and increased risk of development of any form of cancer.

The safety of utensils coated with polytetrafluorethylene-particularly in respect of them causing cancer-has been considered by many national and international regulatory bodies: in all cases a green light has been given to their use.-FRANCIS J C ROE, independent consultant in toxicology, London

1 International Agency for Research on Cancer. Tetrafluoroethylene and polytetrafluoroethylene. Monographs on Evaluation of the Carcinogenic Risk of Chemicals to Humans 1979;19:285-301. 